\title{
AS MARCAS IDENTITÁRIAS DE UM JORNAL DE RÁDIO
}

\section{Beatriz Trezzi Vieira}

\begin{abstract}
Mestranda do Programa de Ciências da Comunicação da Escola de Comunicações e Artes (PPGCOM -ECA), da Universidade de São Paulo (USP). Jornalista graduada pela Faculdade Cásper Líbero, com especialização em Gestão Estratégica em Comunicação Organizacional e Relações Públicas pela ECA-USP.
\end{abstract}

\section{Resumo}

Como atividade de comunicação, o jornalismo não é apenas um mero transmissor de notícias. Por trás do, e em meio ao, discurso de objetividade e imparcialidade adotado pelos veículos jornalísticos, está presente, desde o momento da seleção da notícia até a edição final do jornal, uma carga de opinião e subjetividade que refletem a ideologia dos responsáveis pelo veículo. Por meio da análise de um jornal diário de rádio, este artigo busca compreender como ocorre o discurso jornalístico no meio radiofônico, que marcas revelam a identidade do programa analisado e que vozes e ideologia emergem do discurso ou discursos adotados pelo jornal.

Palavras-chave: Mídia; Rádio; Radiojornalismo; Discurso; Ideologia

\section{Abstract}

As a communication activity, journalism is not only a means of transmitting news. Behind of - and amidst - the objectivity and impartiality discourse adopted by journalists, there lies, from the moment of selection of news to the final edition of a journalistic work, a considerable amount of opinion and subjectivity, both reflecting the ideology of those responsible for a news vehicle. Thorough the analysis of a daily radio news bulletin, this article seeks to understand how the journalistic discourse takes place in the medium radio; which features reveal the identity of this particular news bulletin; and which voices emerge from the discourse, or discourses, of this news program.

Keywords: Media; Radio; Radiojournalism; Discourse; Ideology

EXTRAPRENSA (USP) - Ano V - no 09 dezembro/2011 


\section{Introdução}

Como parte de pesquisa de Mestrado atualmente em desenvolvimento, com foco no radiojornalismo em emissoras católicas de alcance nacional, analisamos neste artigo o Jornal Brasil Hoje (JBH), produzido pela Rádio Aparecida, de São Paulo, em conjunto com cerca de 100 associadas da Rede Católica de Rádio (RCR $)^{1}$. O jornal é transmitido de segunda a sexta-feira, das $7 \mathrm{~h}$ às $7 \mathrm{~h} 30$, simultaneamente pelas emissoras ligadas à RCR, e apresenta os principais destaques nacionais, internacionais, além de notícias da Igreja Católica no Brasil e no mundo. Uma rede de correspondentes nas principais capitais brasileiras informa os ouvintes sobre os destaques do dia em suas regiões. O JBH conta também com uma equipe de editorialistas que tradicionalmente encerram a transmissão, com comentários finais sobre um dos temas do dia. Com 60 anos de história, a emissora responsável pela produção do jornal, a Rádio Aparecida, tem o jornalismo como carro-chefe de sua programação, sempre adotando a opinião como diferencial editorial. Para efeito de análise, foi escolhido o jornal do dia 19 de julho de 2011, uma terça-feira. A edição é a de $\mathrm{n}^{\circ} 6.034$.

A metodologia utilizada é a da Análise do Discurso, tal como apresentada pelo linguista francês Dominique Maingueneau (2004, 2008), associada às contribuições da abordagem de Patrick Charaudeau $(2005,2009)$. Outra base de apoio provém dos pressupostos teóricos do filósofo da linguagem russo Mikhail Bakhtin e seu círculo. Busca-se, por meio da análise de um jornal radiofônico: levantar os traços que apontem para o seu enunciador, ou enunciadores, ou seja, o sujeito, ou sujeitos, do(s) discurso(s) em questão; esclarecer que discursos permeiam os textos jornalísticos transmitidos pelo jornal; e identificar que personagens e vozes emergem ao final da análise.

\section{O ethos e a encenação midiática radiofônica}

Para Maingueneau (2008, pp. 95-103), estar em um determinado discurso não significa apenas proferir um ou outro enunciado, mas adotar um certo tom de voz, um comportamento, um ethos, que está em harmonia com o princípio organizador do estatuto dos enunciadores. Na concepção do autor, o modo de dizer está associado a uma maneira de ser, embora o conceito de ethos não diga respeito apenas àquilo que o enunciador diz de si explicitamente, mas à imagem que é formada com base na cena enunciativa. Como explica Maingueneau, é esse dizer sem ter dito que possibilita a eficácia do ethos, seu poder de despertar a crença, a adesão: o enunciatário, ou co-enunciador é levado a identificar-se com a fala do enunciador, a incorporar um certo modo de ver o mundo, a habitar o mesmo "mundo ético".

Entretanto, ressalta o autor, "há sempre elementos contingentes num ato de comunicação, em relação aos quais é difícil dizer se fazem ou não parte do discurso, mas que influenciam a construção do ethos pelo destinatário" (MAINGUENEAU, 2008, p.16),

EXTRAPRENSA (USP) - Ano V - no 09 dezembro/2011 
como é o caso da interação oral e da transmissão radiofônica. Para Maingueneau, trata-se, em última instância, de uma decisão teórica: saber se se deve relacionar o ethos ao material propriamente verbal, atribuir poder às palavras, ou se se devem integrar a ele - e em quais proporções - outros elementos do conjunto do quadro da comunicação. "O problema é por demais delicado, posto que o ethos, por natureza, é um comportamento que [...] provoca nos destinatários efeitos multissensoriais".

Segundo Patrick Charaudeau (2009), todo ato de comunicação se realiza num determinado ambiente físico que impõe restrições para a realização desse ato.

\footnotetext{
Não é a mesma coisa conversar a dois ou a quatro, em presença de um público ou sem ele, num espaço de proximidade ou de afastamento; a maneira de falar não é a mesma se aquilo a que os interlocutores se referem está se realizando na presença dos dois (o que induz ao comentário) ou de já aconteceu (o que induz ao relato); dirigir-se ao outro oralmente face a face não é a mesma coisa que fazê-lo por escrito ou por qualquer outro meio material (interfone, telefone, ondas de rádio, imagem de vídeo etc.). A cada vez, isto é, a cada situação de comunicação atinente a um contrato, associa-se um dispositivo particular que constitui as condições materiais ad hoc de realização do contrato, em relação a outros componentes e com um quando de restrições. (CHARAUDEAU,2009, p. 104)
}

Segundo argumenta Charaudeau, o dispositivo constitui o ambiente, o quadro, o suporte físico da mensagem, mas não se trata de um simples vetor indiferente ao que veicula, ou de um meio de transportar qualquer mensagem sem que esta se ressinta das características do suporte. Todo dispositivo formata a mensagem e, com isso, contribui para lhe conferir um sentido. "Seria uma atitude ingênua pensar que o conteúdo se constroi independentemente da forma, que a mensagem é o que é independente do que lhe serve de suporte" 4 . Para o autor, o suporte também é um elemento material e funciona como canal de transmissão, fixo ou móvel: pergaminho papel, madeira, uma parede, ondas sonoras, uma tela de cinema ou de vídeo.

No que concerne à comunicação midiática, esses componentes permitem distinguir os três grandes suportes de mídia, que são o rádio, a televisão e a imprensa escrita, segundo as características que lhes são próprias. Por exemplo, a voz para o rádio, a imagem para o suporte televisão, a escrita para o suporte imprensa, teriam, segundo o autor, uma incidência sobre as representações do tempo, do espaço e das condições de recepção construídas por cada uma dessas três mídias.

O rádio é, segundo explica o autor, essencialmente voz, sons, música, ruído, e é esse conjunto que o inscreve numa tradição oral, já que não é acompanhada de nenhuma imagem ou representação figurada dos locutores nem dos objetos que produzem essas vozes, esses ruídos, esses sons. "Sem mencionar os efeitos que os outros sons são suscetíveis de produzir, diz-se que a voz, com suas características de timbre, de entonação, de fluência e de acentuação, é reveladora do [...] 'estado de espírito' de quem fala"'. Dessa forma, o locutor poderá parecer autoritário ou humilde, poderoso ou frágil, emotivo ou senhor

EXTRAPRENSA (USP) - Ano V - no 09 dezembro/2011 
de si, emocionado ou frio, tudo aquilo com que jogam os políticos e os profissionais das mídias.

A oralidade, além disso, é uma interação verbal que é mais ou menos regulada de acordo com as situações e é reveladora do tipo de relação que os interlocutores instauram entre si, de paixão (calor humano) ou razão (distância) de polêmica ou convivência; do tipo de relação que mantêm com o mundo que os cerca e até do tipo de contato que pode estabelecer-se entre as instâncias de emissão e a instância de recepção. Isso tem conseqüências para a encenação midiática.

O acontecimento destinado a tornar-se notícia, deve, por contrato, segundo o autor, produzir-se numa temporalidade a mais próxima possível daquela da instância de recepção (pela restrição da atualidade). A mídia, qualquer que seja, deve gerenciar essa restrição, sabendo que o tempo do acontecimento é diferente - e anterior ao - do tempo da enunciação da instância de produção, o qual é diferente - e anterior ao - do tempo da de consumo da instância de recepção. Assim, o que define a atualidade das mídias é, simultaneamente, o espaço-tempo do surgimento do acontecimento, o qual deve poder ser percebido como contemporâneo por todo e qualquer indivíduo social (inclusive o jornalista) e o espaço-tempo da própria transmissão do acontecimento entre as duas instâncias da informação. Essa co-temporalidade é tratada diferentemente segundo o suporte midiático que a põe em cena, e o rádio é, das três mídias, a que melhor pode fazer coincidir tempo do acontecimento e tempo da escuta. "O rádio é, por excelência, a mídia da transmissão direta e do tempo presente"6.

Com relação às condições de recepção ${ }^{7}$ : essas são próprias a cada tipo de mídia e induzem a formatações e apresentações diferentes da informação. Quanto ao rádio, ao jogar com as características próprias à oralidade, à sonoridade e à transmissão direta, cria duas cenas de fala: uma de descrição e de explicação dos acontecimentos do mundo, outra de troca de intervenções, de opiniões, de pontos de vista.

\footnotetext{
"O ouvinte não dispõe de imagens, as reconstitui graças a seu poder de sugestão, de evocação, favorecendo uma reconstrução imaginada livre, com o auxílio de associações pessoais (o que não é o caso da televisão que mostra e, portanto, impõe)." MAINGUENEAU, 2008, p.108
}

No que concerne à explicação, o ouvinte, que não dispõe do suporte escrito que lhe permita fazer um vai-vem em sua leitura, deve pôr em funcionamento um tipo de compreensão particular que se baseia numa lógica de justaposição, diferente daquela da leitura, pelo fato de que o desenvolvimento explicativo do discurso não pode proceder, como na escrita, por subordinação e encaixe dos argumentos. Esse fenômeno se acentua quando se trata de debates, entrevistas, pois o que se teria nesse caso é uma oralidade cheia de interrupções, hesitações, retomadas, redundâncias, em suma, todas as características próprias à interação verbal, mesmo que nas mídias elas sejam particularmente orquestradas.

EXTRAPRENSA (USP) - Ano V - no 09 dezembro/2011 
Para Charaudeau, todas essas características próprias ao dispositivo do rádio permitem compreender por que essa mídia, universo por excelência da voz, é particularmente eficaz quando produz:

\begin{abstract}
uma palavra de informação fatual imediata (os flashes de informação), uma palavra polêmica nas entrevistas e debates, uma palavra intimista em certas conversas, que se aproximam da confissão, uma palavra de análise espontânea feita de comparações e metáforas, enfim, uma palavra romanesca nas narrativas de belas histórias, mesmo que, aí a magia do verbo não seja o mais importante. (CHARAUDEAU, 2009, p. 109)
\end{abstract}

\title{
Linguagem, jornalismo e ideologia
}

Para Bakhtin (1979, pp. 17 a 24) e seu círculo, todo discurso humano é uma rede complexa de interrelações dialógicas com outros enunciados e a língua, portanto, reflete as relações dialógicas das diversas interações verbais. Nenhum discurso é exclusivo a um único sujeito falante, uma vez que outras vozes que antecederam aquela atividade discursiva estão presentes na palavra do locutor.

"Voz" foi o termo escolhido por Bakhtin para referir-se à consciência falante presente nos enunciados. Por meio do estudo das "vozes", é possível ver ou entrever as diferentes consciências falantes ou vozes presentes em um determinado discurso. Nessa perspectiva, o discurso jornalístico seria então marcado por uma pluralidade de vozes nem sempre simétricas. Ele torna-se uma teia dialógica constituída de muitas vozes que se completam, se contradizem, se aproximam, se distanciam, se reiteram, com posicionamentos ideológicos semelhantes ou contraditórios.

O círculo concebia a ideologia como dialógica, já que vai sendo construída em movimento vivo, relacionada com a questão da constituição dos signos e da subjetividade. A concepção de ideologia para o grupo passa necessariamente pela constituição da palavra como sendo um signo ideológico por excelência. Isso porque a palavra extrapola o campo material do seu significado físico-material e adquire valores. Tudo que é ideológico possui um significado e remete a algo situado fora de si mesmo, ou seja, tudo que é ideológico é um signo.

Assim como a camiseta assinada pelo jogador ganha novo significado, o martelo e a foice, quando colocados juntos em uma bandeira comunista, passam a significar muito mais do que meros instrumentos de trabalho. Refratam outra idéia, outra realidade, viram signos. O martelo e a foice que existiam na bandeira da extinta URSS produziam a idéia de que o Estado Soviético era construído pela aliança dos trabalhadores urbanos com os rurais. "Assim, a bandeira dizia que a união de operários com os camponeses tornava possível a existência da União das Repúblicas Socialistas Soviéticas" (CITELLI, 2001, p.27).

O alimento pão, no contexto religioso, denota o corpo de Cristo, assim como a

EXTRAPRENSA (USP) - Ano V - no 09 dezembro/2011 
maçã se tornou símbolo do pecado e, a pomba, da paz. O ponto de vista, o lugar valorativo e a situação do signo são sempre determinados historicamente. Para Bakhtin, o lugar de constituição do signo e de materialização se dá na comunicação contínua e na interação verbal. Daí ser a linguagem o lugar mais claro e completo da materialização do fenômeno ideológico.

A representação do mundo é mais bem expressa por palavras e reproduzida por um ser humano na presença de outro ser humano, dizia o autor. Essa concepção contrapõe visões que pregam que há uma ideologia dominante em detrimento de uma ideologia dominada, numa relação subalternizada. Há tantas ideologias quantas forem as visões de mundo, que na prática representariam interesses de diversos grupos sociais. Em cada uma delas, os signos se revestem de sentidos próprios, produzidos a serviço dos interesses daquele grupo.

Bakhtin distingue ideologia oficial de ideologia do cotidiano. A oficial, produzida na superestrutura, é entendida como relativamente dominante, que procura introduzir uma concepção única de produção de mundo. Já a ideologia do cotidiano é considerada como a que brota nos encontros casuais e fortuitos, onde nascem os sistemas de referência, na proximidade social com as condições de produção e reprodução da vida.

Vistos nessa perspectiva, os discursos não são neutros, uma vez que as palavras estão carregadas de valores ideológicos. Os discursos servem para legitimar certos pontos de vista, seja de um país ou grupos sociais ou das ciências.

Na concepção bakhtiniana, a linguagem é, portanto, veiculadora de ideologia. É nessa relação que Bakhtin defende que qualquer, até mesmo o mais imperceptível, acontecimento ou mudança social repercute na língua. As palavras guardam em si uma certa memória social, pois uma mesma palavra figura em contextos diversamente orientados. Isso explica, portanto, como as palavras engendram lutas de classe, pois são tecidas por fios ideológicos, e como os discursos veiculam ideologia e a fala se constitui em uma arena de debates de conflitos. Aquelas diversas vozes que ecoam dentro de um dizer se dão entre a interação verbal e se materializam no dialogismo com outras idéias.

Dessa forma, a notícia é socialmente construída, não apenas pelo fato de se valer da linguagem para transmitir, informar e formar opiniões, mas também pelo fato de que é produzida por repórteres e editores, que necessariamente têm de tomar decisões nas diversas instâncias do processo de produção de um jornal.

Tão importantes quanto o evento noticiado são também as operações envolvidas nos critérios de seleção da notícia. Ela será escolhida se for vista sob certo enfoque de representação, o que envolve um ato de interpretação ideológica. Dessa forma, a notícia passa por um processo de mediação desde o momento da seleção até ser publicada.

EXTRAPRENSA (USP) - Ano V - no 09 dezembro/2011 
Os jornais não publicam simplesmente o que acontece, mas o que pode ser considerado e apresentado como merecedor de publicação. O que vai ser publicado é fruto de critérios jornalísticos, ou critérios de noticiabilidade, que levam em conta se a notícia é de interesse público, sua atualidade, ineditismo, quais são os personagens envolvidos, o grau de impacto sobre a sociedade, se tem alguma curiosidade, entre outras características. São os chamados "valores-notícias" (WOLF, 2001, pp. 193-228 ), que estão por trás da seleção editorial e servem como balizadores do trabalho da imprensa.

É preciso levar em conta, ainda, que o jornal, seja ele de qualquer veículo ou suporte, também em geral é um produto mercadológico, seguindo obrigatoriamente a linha editorial de cada empresa, que por sua vez representa um determinado grupo de controladores ou proprietários e mantém relações comerciais com anunciantes. Todo esse contexto em que a notícia é produzida representa as condições de produção do discurso jornalístico, que é, portanto, portador de várias vozes. Não emite apenas a voz do dono do veículo, mas também a dos que o editam, vendem, compram ou os que sobre ele têm possam ter alguma ascendência, como é o caso do Estado.

\section{Análise do programa}

O jornal inicia com o cumprimento e apresentação dos locutores, citação de três emissoras associadas e chamada das manchetes do dia. Outras emissoras, de diversas regiões, serão citadas ao longo do programa, em geral na chamada para o intervalo e no retorno desse. As manchetes do início do programa contam com a participação dos correspondentes em Brasília, Belém, Salvador, Santa Catarina e São Paulo. O tom adotado pelos apresentadores busca demonstrar a seriedade, objetividade e distanciamento críticos atribuídos ao noticiário jornalístico, embora, ao mesmo tempo, a linguagem radiofônica tenha de empregar uma certa atitude conversa com o público, falando ao pé do ouvido, como se estivesse contando uma história ao ouvinte. Dessa maneira, o jornal é iniciado com um "Olá, bom dia" e o ouvinte é tratado por "você". A prestação de serviço é outra preocupação própria do meio rádio, em particular da rádio produtora do jornal, a Aparecida. Daí decorre o fato de diversas vezes, ao longo do jornal, ser informada a hora certa.

Os temas em destaque no dia começam com a série de escândalos de corrupção no Ministério dos Transportes, que haviam eclodido no início do mês de julho, causando demissões em cascata no próprio ministério e em órgãos e instituições prestadoras de serviço do setor. A primeira nota, de Política, chama atenção para e deixa clara a hesitação da presidente Dilma Roussef na condução da crise, ao voltar atrás pela segunda vez nas indicações para diretoria do Departamento Nacional de Infraestrutura de Transportes (Dnit), cujo diretor-executivo, Luiz Antônio Pagot, havia sido destituído no início do mês. A desistência na indicação para um novo diretor de Finanças do órgão veio acompanhada do anúncio de que o Planalto modificaria as regras para as indicações aos cargos de comando do Dnit, feitas até então automaticamente por sua diretoria-executiva, com apro-

EXTRAPRENSA (USP) - Ano V - no 09 dezembro/2011 
vação final do governo.

A nota, com trechos de entrevista de um dos líderes da oposição, o senador Álvaro Dias (PSDB-PR), adota tom irônico desde a manchete, pela própria entonação do correspondente em Brasília: "Sem condições para estancar a corrupção no Dnit, a presidente Dilma Roussef, modifica as regras para a indicação dos novos diretores (voz se torna mais grave, alongando o "o" na terceira sílaba da palavra diretores). O ethos crítico, que inicia a nota afirmando que a presidente já não tem "condições de estancar a corrupção" no órgão é confirmado pela entrevista com o líder da oposição, que sugere até mesmo a "compra do silêncio" do ex-diretor do Dnit, que à época prestava esclarecimentos em depoimentos ao Congresso. $\mathrm{O}$ correspondente em Brasília finaliza, voltando à entonação de voz irônica, informando que a modificação nas regras das indicações foi determinada pelo Planalto, depois que o primeiro substituto acabara perdendo o cargo, pois descobriu-se que sua mulher era dona de empreiteira que faturou milhões fazendo negócios com o Ministério e o Dnit.

De volta à central de produção, somos informados de que a oposição está bem próxima de conseguir a abertura de uma CPI para investigar as denúncias envolvendo o Ministério dos Transportes e órgãos ligados a ele. Essa nota também servirá de base para o editorial do dia, veiculado ao final da edição.

A nota a seguir também é relacionada è editoria de Política, informando que nenhum senador compareceu à última sessão do Senado antes do recesso parlamentar, realizada no dia anterior (uma segunda-feira). Com um tom de voz que mantém o ethos sério adotado pelo jornalismo de forma geral, os locutores narram, porém, um fato que em si se releva absurdo, o de que os senadores não se dignaram nem mesmo a comparecer ao plenário para encerrar "o que nem foi possível começar". O sentido neste caso é dado pelo que está subtendido e não pelo que é dito explicitamente ou pela forma como é dito. Os locutores informam, ao final, que, durante o recesso parlamentar, o Congresso manterá sua parte administrativa trabalhando e que foi criada uma comissão, que estará "de prontidão" para analisar questões urgentes.

A próxima notícia mantém-se na editoria de Política, desta vez informando sobre um ação do governo brasileiro para "melhorar o diálogo" com a população da região do entorno da futura hidrelétrica de Belo Monte que será afetada direta ou indiretamente pela construção da usina. Diante de manifestação de rua contrária à construção da usina realizada em São Paulo por parte de alguns moradores da região, o governo decidiu realizar um mutirão com prestação de serviços em 11 municípios. Mais uma vez, em tom sério, os locutores narraram um fato que fala por si: em lugar de agir com antecedência, o governo tenta "dialogar" e "melhorar o relacionamento" com a população da região um mês depois que o Ibama concedeu a licença ambiental para que o consórcio vencedor comece os serviços, ou seja, às vésperas do início das obras.

EXTRAPRENSA (USP) - Ano V - no 09

dezembro/2011 
Outra nota referente a uma ação do governo é a que informa que deve ser editada medida provisória para agilizar a triagem e a destinação do material apreendido nas fronteiras, como drogas e carros. O material apreendido, esclarece o jornal, fica em depósitos públicos "por anos". A seção de Política finaliza com informação de que o presidente da OAB de São Paulo, Luiz Flávio Borges d'Urso vai se filiar ao PTB e sair candidato a prefeito da capital em 2012. A nota informa que os petebistas mudaram de candidato depois que Gabriel Chalita (político da região do Vale do Paraíba, onde é produzido o jornal), inicialmente cotado, decidiu ingressar no PMDB.

A seção de Economia começa com notícia sobre o novo sistema de compensação de cheques, que deverá ser uniformizado em todo o Brasil, eliminando diferenças regionais responsáveis pela demora de até 20 dias úteis, em algumas regiões, para a compensação. $\mathrm{O}$ novo sistema digital implantado também é mais seguro, diz o jornal, já que o cheque não precisa ser transportado.

Segue notícia que parece deslocada do contexto da editoria, sendo mais talhada para uma editoria de Geral. A nota fala sobre negociações do governo paulista e a AES Eletropaulo para reduzir os frequentes cortes de energia verificados ao longo no ano na capital e na região metropolitana de São Paulo. A informação é de que as duas partes defendem propostas diferentes sobre o montante dos investimentos e o número necessário de contratações para melhorar o fornecimento de energia. Em citação indireta, é atribuída ao secretário estadual de Energia a afirmação de que os números propostos pela Eletropaulo são insuficientes para solucionar o volume de problemas verificado na região coberta pela concessionária. Entrevistado, o diretor da companhia afirma, em citação direta, que tanto a proposta da empresa como a do governo estadual são "convergentes".

Outra nota de Economia revela resultado de pesquisa que apontou os mais rentáveis investimentos do Brasil desde a implantação do Plano Real, ressaltando que a poupança, investimento mais tradicional do Brasil, ficou em terceiro lugar, depois dos fundos de renda fixa e das ações em bolsa. Segue notícia informando que a venda de cotas de consórcios de veículos, imóveis e serviços aumentou $41 \%$ no período de janeiro a maio deste ano, em relação ao mesmo período de 2010.

A primeira reportagem regional vem de Santa Catarina. O correspondente informa sobre o fim da paralisação de dois meses e dois dias dos professores da rede estadual de ensino, considerada a terceira mais longa do magistério no Estado. Em citação indireta, o sindicato da categoria afirma que o estado de greve continua.

Sem vinheta específica que introduza as notícias relacionadas à Igreja Católica, segue chamada para a correspondente que estava cobrindo o $7^{\circ}$ Mutirão de Comunicação convocado pela Conferência Nacional dos Bispos do Brasil (CNBB), realizado naquela semana, na PUC do Rio de Janeiro. A repórter entrevista a presidente da Signis Brasil, en-

EXTRAPRENSA (USP) - Ano V - no 09

dezembro/2011 
tidade criada no ano passado para congregar os veículos e profissionais da comunicação católicos no país. A nota conta com uma autorreferência, já que a presidente da Signis cita o Jornal Brasil Hoje como uma importante iniciativa de convergência e de trabalho conjunto das emissoras católicas no Brasil. Em seguida, a vinheta "A força do rádio. A importância da união. RCR, Rede Católica de Rádio. Emissoras a serviço da fé e do Brasil" reforça a mensagem passada na nota.

Na volta do intervalo, chamada para o correspondente em Belém. Ele relata encontro dos arcebispos e cardeais que formam o conselho de administração de uma fundação católica latino-americana, com missão de assistir populações carentes da região. O entrevistado é o arcebispo de Belém, que integra o conselho administrativo da fundação. Ele explica que, durante a reunião, serão analisados cerca de 200 projetos apresentados por arquidioceses latino-americanas, parte dos quais receberá verbas a partir de setembro. $\mathrm{O}$ correspondente conclui citando alguns dos projetos locais que serão analisados durante o encontro e destaca que o evento inclui reuniões, celebrações, visitas às igrejas históricas de Belém e aos monumentos da cultura paraense. A forma como a nota é encerrada passa uma idéia mais festiva que assistencialista do evento.

Entra nota sobre o Ceará, onde a polícia civil prosseguia em greve desde o início do mês, o que levou o governo do estado a criar uma delegacia para atender a pessoas com necessidades especiais. A nota ressalta que a greve foi considerada ilegal pelo Tribunal de Justiça do estado.

Seguem informações do correspondente em Salvador. Atentado a posto da secretaria estadual da Fazenda, no interior da Bahia, matou dois e feriu um policial militar. O próprio correspondente lê nota da secretaria sobre o ocorrido. A secretaria afirma que está tomando as "providências cabíveis" para esclarecer o caso, já que os bandidos, que eram cinco, conseguiram escapar.

Mais notas regionais lidas pelos locutores, com foco nos prejuízos deixado pelas chuvas em excesso em Pernambuco e na Paraíba. Na sequência, a previsão do tempo, que tem uma abrangência nacional. Uma especialista do Instituto de Pesquisa Tecnológicas (Inpe) passa os prognósticos para todas as regiões do país. Entra chamada para o "comentário final" e para intervalo. Na volta do intervalo, chamada para o comentário de um dos editorialistas do jornal. O editorial faz uma análise da principal notícia do dia, sobre os desdobramentos da crise no Ministério dos Transportes.

O editorialista inicia suas considerações com um tom conciliador, de entendimento. Dá razão aos partidos que formam uma aliança política vencedora em quererem participar do governo. Utiliza o vocábulo "naturalmente" para indicar sua concordância com os que reivindicam esse direito. No entanto, logo após iniciar essa linha de raciocínio, ressalta que, no Brasil, em geral essa participação não significa dividir responsabilidades

EXTRAPRENSA (USP) - Ano V - no 09 dezembro/2011 
e trabalho em prol da população, mas (o termo empregado é "agora", no sentido de "entretanto") apropriar-se do dinheiro público, como se se estivesse repartindo um "botim" de guerra e como se fosse "propriedade privada". Por meio desse esquema argumentativo e da utilização de metáforas, o autor faz a balança pender para o lado negativo da atividade política. Revelam-se atitudes ou perspectivas contrárias no fazer político: as daqueles que atuam para o bem comum e as dos que veem na atividade política um meio para enriquecer e tirar proveito próprio.

O autor procura então citar uma série de situações e fatos (um "festival de irregularidades") que comprovam que os políticos envolvidos no caso do Ministério dos Transportes e seus departamentos, como o Dnit e Valec, fazem parte do segundo grupo. Passa a utilizar então termos bem mais pesados como "apaniguados", "milhardários", "corruptos" e "ladroagens", ao comentar algumas das informações que vieram a público desde o início da crise. A conclusão seria que, ao ficarem comprovadas as ações delituosas dos envolvidos, esses deveriam ser punidos. No entanto, o autor lembra que um dos envolvidos no caso decidiu "peitar" o governo federal, ao ameaçar implicar petistas no esquema de corrupção e até acusar a presidente de ser "beneficiária indireta" do esquema de propina. O editorialista encerra com uma constatação em tom de advertência: apesar dos fatos apurados e das evidências apontadas, nenhum dos envolvidos está sendo investigado ou processado pela Justiça. Ou seja, ao que tudo indica, poderão "gozar" em liberdade do "fruto" de seu "trabalho" no governo.

\section{Considerações finais}

Ao analisar o Jornal Brasil Hoje, produzido pela Rádio Aparecida com a colaboração de emissoras associadas, verifica-se a presença de diversas vozes, direta ou indiretamente, por meio de entrevistas ou citações, mas acreditamos haver uma voz dominante, dessa forma sem que haja verdadeiramente polêmica. Pelo próprio estilo da emissora que produz o jornal, existe uma opção por um jornalismo marcado pela opinião em diversos graus: seja subtendido no noticiário informativo, ou explícito, no editorial. Assim, está-se diante de um jornal em que existe o dialogismo, representado pelas diversas vozes ouvidas nas entrevistas, mas sem a ocorrência de uma verdadeira polifonia, caso em que se verificaria a ocorrência de vozes polêmicas e contraditórias, com pontos de vista se defrontando de maneira equilibrada. Por meio de uma linha editorial já pré-estabelecida, solidificada, o fazer jornalístico dos responsáveis pelo JBH permite entrever uma postura argumentativa coerente e forte, que sabe orientar seus enunciados de forma a convidar os ouvintes a "jogar o seu jogo", a concordar com seus pontos de vista, ou em última instância, com suas posturas ideológicas.

EXTRAPRENSA (USP) - Ano V - no o9 dezembro/2011 


\section{Referências bibliográficas}

BAKHTIN, M. Marxismo e Filosofia da Linguagem. São Paulo: Hucitec, 1979.

CHARAUDEAU, P. Discurso das Mídias. São Paulo: Contexto, 2009.

Discurso Político. São Paulo: Contexto, 2005.

CITELLI, A. Linguagem e Persuasão. Série Princípios. São Paulo: Ática, 2004.

DISCINI, N. O Estilo nos Textos. São Paulo: Contexto, 2003.

GOMES, M. R. Jornalismo e Ciências da Linguagem. São Paulo: Edusp. 2000.

MAINGENEAU, D. Análise dos Textos de Comunicação. São Paulo, Cortez, 2004.

. A propósito do Ethos. In: MOTTA, A. R.; SALGADO, L. (Orgs.). Ethos Discursivo. São Paulo: Contexto, 2008, pp 11-29.

WOLF, M. Teorias das Comunicações de Massa. Lisboa: Editorial Presença, 2001.

\section{Notas}

${ }^{1}$ Associação de emissoras vinculadas a instituições da Igreja Católica, como arquidioceses, dioceses, congregações religiosas e grupos de cristãos leigos. Disponível em http: //rcr.org.br/paginas/ver/perfil-da-rcr-2. Acesso em 31 de julho de 1011.

${ }^{2}$ Grifo do autor.

${ }^{3}$ MAINGUENEAU, 2008, p.16

${ }^{4}$ Idem, p. 105

${ }^{5}$ Ibid, p. 106

${ }^{6}$ MAINGUENEAU, 2008, p. 107. Grifos do autor.

${ }^{7}$ Grifo do autor. 